\title{
PENINGKATAN KREATIVITAS MELALUI METODE PEMBELAJARAN INKUIRI (Penelitian Tindakan Anak Usia 5-6 Tahun Di PAUD SPS ARRAYAN Tahun 2017)
}

\author{
Padilah \\ Program Studi Pendidikan Guru Pendidikan Anak Usia Dini \\ Universitas PGRI Palembang \\ E-mail: padilahutama@gmail.com
}

\begin{abstract}
Abstrak: The purpose of this research was to describe the implementation process inquiry and to understand improving creativity of children 5-6 years old through inquiry. The study was conducted on group A Kindergarten with of seventeen children. This study used action research methods by Kemmis and Taggart which consist of 4 stages (plan, action, observation and reflection). The study consisted of two cycles, each cycles consisting of 8 sessions. Data collecting techniques used observation, field notes and documentation. Data analysis using quantitative and qualitative data. Quantitative data analysis with descriptive statistics that compare the result obtained from the first cycle and the second cycle. Analysis of qualitative data by analizing data from the observation, fields notes and documentation during the study to the steps of data reduction, data display and data verification. The result of this study showed that there was the improving creativity through inquiry with score in pre cycle 24,9 had improvement to 44,9 and become 67,7 in cycle II and excellent growing category.
\end{abstract}

Keywords: Creativity, Inquiry, Action Research

\begin{abstract}
Abstrak: Tujuan hasil penelitian ini adalah mendeskripsikan proses metode pembelajaran inkuiri dan untuk mengetahui peningkatan kreativitas anak usia 5-6 Tahun melalui pembelajaran inkuiri. Penelitian ini dilakikan pada anakkelompok B yang berjumlah 15 orang. Penelitian ini adalah penelitian tindakan dengan metode Kemmis dan Taggart yang terdiri dari 4 tahap yaitu (rencana, tindakan, observasi dan refleksi). Penelitian ini terdiri dari 2 siklus masing-masing siklus sebanyak 8 pertemuan. Teknik pengumpulan data menggunakan observasi, catatn lapangan, dan dokumentasi. Analisis data menggunakan kuantitatif dan kualitatif. Analisis data kuantitatif dilakukan dengan deskripsi statistic untuk membandingkan pra siklus sampai siklus II. Tahaptahap analisis kualitatif adalah reduksi data, display data dan verifikasi. Hasil penelitian menunjukkan terdapat peningkatan Kreatifitas melalui Metode Inkuiri dengan skor pada pra siklus 24,9 meningkat menjadi 44,9 pada siklus I, dan mengalami peningkatan sebesar 67,7 pda siklus II dengan kategori berkembang sangat baik.
\end{abstract}

Kata Kunci: Kreativitas, Metode Inkuiri, Penelitian Tindakan Kelas 


\section{PENDAHULUAN}

Golden age merupakan usia emas bagi anak usia dini, dengan rentang usia lahir sampai dengan usia enam tahun. Pada tahap usia dini, anak memiliki pertumbuhan dan perkembangan yang sangat pesat. Kemampuan otak anak berkembang hingga $40 \%$ pada usia 4 tahun dan akan berkembang menjadi $80 \%$ pada usia 8 tahun. Anak usia dini adalah $a$ unique person (individu yang unik), karena anak usia dini mempunyai banyak potensi, serta memiliki kreativitas yang perlu dikembangkan dan di stimulasi.

\section{Pengajaran yang efektif} sangat berpengaruh pada kreativitas anak, anak terdorong dari aktivitas yang ditemuinya dalam kehidupan nyata, sehingga terbentuk forum diskusi, dimana adanya interaksi social dan keingintahuan atas suatu jawaban, yang pada akhirnya anak akan termotivasi untuk melakukan kegiatan, sehingga memunculkan kreativitas dalam berpikir kreatif. Alkaterini Michalopoulou. Dalam penelitiannya yang berjudul InquiryBased Learning through the Creative Thingking and Expression in Early
Years Education. menjelaskan dalam penelitiannya untuk meningkatkan kreativitas anak, dengan cara eksplorasi dengan tema yang menarik, dengan eksplorasi yang dilakukan anak dapat memberikan tanggapannya, pikiran, gagasan, dan perasaan anak melalui seni menggambar. Dengan gambar yang anak lakukan di harapkan anak dapat mengekspresikan ide-ide dengan cara menceritakan gambar tersebut, sehingga anak dapat berimajinasi.

Hong-Yi le. Inquiry-Based Teaching in Second and Foreign Language Pedagogy. Penelitian ini menunjukkan bahwa mengajar berbasis inkuiri dapat menginspirasi dan mampu mengembangkan kemampuan siswa dengan melibatkan linguistik dan kognitif mereka. Pertanyaan terstruktur menunjukkan siswa untuk menghubungkan, menerapkan, menganalisis dan menciptakan. Beberapa variable yang mungkin mempengaruhi keberhasilan pelaksanaan pengajaran berbasis inkuiri termasuk pembelajaran kelompok, dan kemampuan untuk menciptakan lingkungan belajar yang 
santai dan menyenangkan. Botz Krummeheuer dalam penelitiannya yang berjudul Explanning the mathematical creativity of young boy, an interdisciplinary venture between mathematics education and psychoanalysis menjelaskan bahwa kreativitas yang dilakukan dengan cara eksplorasi siswa melalui lingkungannya, dan guru juga menggunakan metode bermain untuk meningkatkan anak dalam pembelajaran matematika. Angela Eckhoff dalam penelitiannya yang berjudul Creativity In Early Chidhood Classroom: menjelaskan bahwa peran guru sangat mempengaruhi anak dalam mengembangkan kreativitas, adapun kreativitas yang dikembangkan yaitu melalui seni, contoh kegiatan seni yang di lakukan antara lain seni melukis, seni menggambar yang bertujuan agar anak berpikir imajinatif.

Anna Lehtonen.at.al dalam penelitiannya yang berjudul Promoting Creativity In Teaching Drama menjelaskan bahwa pembelajaran kreatif dapat ditingkatkan melalui kegitan drama.
Guru perlu mempersiapkan proses kegiatan pembelajaran yang kreatif, dimana hasil dari kegiatan tersebut tidak dapat atau diluar prediksi guru. Melalui drama tujuan guru untuk memberikan dan membuat waktu dan tempat sebagai solusi dan ide kreatif dalam pembelajaran drama.

Drama juga dapat dijadikan sebagai kegiatan yang baik untuk berkolaborasi dan meningkatkan kepedulian siswa. Dari hasil penelitian relevan yang sudah di jelaskan, bahwa melalui kegiatan pembelajaran inkuiri yang dilakukan, dengan cara menentukan tema, anak ikut serta untuk melihat hasil pengamatan yang dilakukan yaitu dengan gambar yang dihasilkan siswa, dan penelitian sebelumnya lebih melihat linguistic dan kognitif siswa. Pada penelitian relevan kreativitas sebelumnya lebih menjelaskan bahwa kegiatan dilakukan dengan eksplorasi yang menekankan pada pembelajaran matematika, seni melukis, dan seni drama untuk meningkatkan kreativitas anak dalam berpikir imajinatif, tetapi belum berfokus pada kreativitas melalui metode 
pembelajaran inkuiri. Berbeda dengan penelitian yang akan dilakukan lebih berfokus pada berpikir kreatif dengan menggunakan metode pembelajaran inkuiri. Sehingga perlunya diadakan penelitian tentang peningkatan kreativitas melalui metode pembelajaran inkuiri. Berdasarkan pengamatan yang dilakukan di PAUD SPS Arryan Palembang anak usia 5-6 tahun yang berjumlah 15 anak, yang terdiri dari 8 anak perempuan dan 7 anak laki-laki. Dari hasil pengamatan tersebut masih terdapat sebagian anak yang belum memiliki kemampuan untuk berpikir kreatif, dimana terdapat 12 anak (86,66\%) belum mampu menghasilkan ide baru, menginovasi produk, menyelesaikan masalah dan belum mampu menciptakan atau menghasilkan produk. Berdasarkan hasil penelitian relevan dan fakta dilapangan yang telah dipaparkan maka perlu diadakan penelitian tindakan tentang peningkatan kreativitas melalui metode pembelajaran inkuiri pada kelompok B di PAUD SPS Arrayyan Palembang.

\section{KREATIVITAS}

Konsep dan bentuk kreativitas setiap manusia berbeda dengan individu yang lain, begitu juga kreativitas orang dewasa dan anak usia dini. Kreativitas pada anak usia dini mempunyai cirri khasnya sendiri, kreativitas anak dikoridori oleh keunikan gagasan dan tumbuhnya imajinasi serta fantasi anak, oleh karena itu orang yang berada disekitar anaklah yang dapat menstimulasinya. Menurut Porandokht Fazelian, Saber Azimi (2013).

Creativity in schools he has defined it as a complex behavior in which a person utilize his or her mental resources in special way in order to come up with a new adaptive product. Which is real. Therefore, he emphasizes on the flowing elements as based of creativity.

- Being able to go through presses for inventing something new

- Thingking useful ideals

- $T u$ be able to heightened perception of our surrounding for unique fruitfrul end

- The ability to make connections from various pieces of information in a novel way, and to bring these ideas to a fruitfrul result 
- New ideas, improvements, innovations are all from ofcreativity

- Invention or expression of that which is both useful and original to the Creator

- Mental process

- Usually the presence of problem to be urgently solved.

Menurut Angela Eckhoff, Creativity is the ability ti think in original ways, related to imagination, the ability ti produce something uniqe, original, a means to express yourself, ability to come up with new solutions and ideas to solve difficult problems.

Pernyataan tersebut dapat

diartikan bahwa kreativitas adalah kemampuan untuk berpikir dengan cara yang asli, terkait dengan imajinasi, kemampuan untuk menghasilkan sesuatu yang unik, asli, dan sarana untuk mengekspresikan diri, kemampuan untuk menciptakan sesuatu yang asli bukan dari apa-apa, tidak tahu/ masih kosnong, kemampuan untuk memunculkan solusi baru dan ide-ide untuk memecahkan masalah-masalah yang sulit.

Menurut Fionna S. Baker Creativity is then using that imagination to solve problems-call it, applied imagination. Pernyataan ini dapat diartikan bahwa kreativitas adalah kemampuan menggunakan imajinasi untuk menyelesaikan masalah yang diterapkan dengan imajinasi berpikir.

Menurut Carl Rogers denefition of creativty as " the emergence in action of the individual on the one hand, and materials events, people or circumstances of his life on the other". Pernyataan diatas dapat diartikan bahwa kreativitas dimaknai sebagai "kemampuan munculnya tindakan dari dalam individu untuk menciptakan sesuatu menggunakan bahan dan sangat dipengaruhi oleh hubungan/interaksi dengan orang lain. Sibel Demir at.al

Creativity is a talent on the orther hand, opportunites should be given starting from young ages for is appearance and development creativty. Creativty should be described as skills that involve working alone and cooperatively, giving time for listening thingking and focusing seriously when facing problems.

Pernyataan diatas dapat diartikan bahwa Kreativitas adalah kemampuan yang harus dikembangkan mulai dari usia muda. Kreativitas harus digambarkan sebagai keterampilan yang 
melibatkan bekerja sendiri dan bekerja sama dengan orang lain, memberikan waktu untuk berpikir kreatif dan fokus ketika menyelesaikan masalah.

\section{METODE INKUIRI}

Inkuiri adalah suatu metode "sains sebagai suatu proses dimana anak-anak belajar keterampilan seperti mengamati, menyimpulkan dan bereksperimen". Proses sains tersebut melibatkan proses berpikir kreatif untuk mengembangkan pemahaman anak tentang sains. Sains sebagai inkuiri adalah pendidikan dasar sains untuk mengontrol pengendalian dan organisasi utama untuk dipilih sebagai kegiatan siswa. Anak-anak yang berada pada level kemampuan sains seharusnya dapat menggunakan saintific inquiry dan dapat mengembangkan kemampuan untuk berpikir dan bertindak yang dihubungkan dengan inkuiri terkait dengan anak bertanya, merencanakan kegiatan, mengamati, menggunakan alat-alat untuk mengumpulkan data, berpikir kreatif dan logis tentang hubungan bukti-bukti dan penjelasan serta dapat merekonstruksi dan menjelaskan pertanyaan-pertanyaan scientific.

$$
\text { Metode inkuiri yang }
$$
dipergunakan untuk pembelajaran sains yaitu anak memiliki keterampilan mengamati, menyimpulkan dan eksperimen. Dari proses metode inkuiri ini anak dapat berpikir kreatif dengan caraanak dapat bertanya, merencanakan kegiatan yang akan dilakukan dan anak dapat menceritakan kegiatan yang akan dilakukan.

Penempatan nilai dalam discovery inquiry ilmiah, yaitu mengetahui banyaknya kemampuan dan proses termasuk dalam pengembangan sains. Ketika anak terinspirasi dan tertarik pada sesuatu, maka anak tidak puas dengan satu jawaban. Menanggapi hai ini anak mencari petunjuk untuk mencari jawaban. Sains diperkenalkan sebagai suatu konsep dan pemikirn untuk mencapai pertanyaanpertanyaan yang tumbuh pada pemikiran anak. Metode pembelajaran inkuiri yaitu dimana anak terinspirasi untuk anak bertanya dan melakukan pengamatan, untuk 
memecahkan masalah yang dihadapinya.

Metode pembelajaran inkuiri pada anak usia dini dimana anakanak melakukan penyelidikan untuk memahami terhadap suatu objek, kemudian berbagi hasil dengan orang lain. Anak melakukan percobaan sederhana untuk mengetahui jawaban. Contoh percobaan yang dilakukan anak dengan membandingkan hewan atau pohon. Ketika anak usia dini mempunyai keingintahuan akan suatu objek, anak terdorong untuk melakukan eksplorasi dengan melakukan penyelidikan dan menemukan jawaban dengan memperbandingkan objek lain, adapun hasil dari yang ditemukan dapat diceritakan dengan orang lain.

Pembelajaran berbasis Inkuiri pada anak usia dini melibatkan proses pengamatan, baik dilakukan anak secara individu maupunkelompok untuk menemukan jawaban atas pertanyaan-pertanyaan atau permasalahan yang dihadapi anak pada proses belajar, pengamatan yang dilakukan dengan cara eksperimen. Pengamatan dan eksperimen merupakan bagian penting dari pembelajaran inkuiri karena pengamatan melibatkan keingintahuan anak untuk mengekplorasi benda-benda yang ada di sekitar anak, mengamati bentuk-bentuk dan warna, gerak, peristiwa-peristiwa atau kejadian fenomena-fenomena yang terjadi secara alami. Dalam hal ini guru harus mampu mendorong, membimbing dan memotivasi anak untk menyelesaikan masalah sehingga dapat memunculkan anak dalam berpikir kreatif.

Metode pembelajaran inkuiri ilmiah (Science inquiry learning model) merupakan salah satu model yang memenuhi karakteristik dasar suatu model dan kondusif bagi pengimplementasian metode konstruktivisme. Inkuiri merupakan suatu proses untuk memperoleh informasi melalui observasi atau eksperimen untuk memecahkan suatu masalah dengan mengunakan kemampuan berpikir kritis dan logis. Pembelajaran inkuiri lebih pada metode konstrultivisme, kegiatan yang dilakukan untuk memecahkan masalah dalam kemampuan anak 
berpikir kreatif, kritis, dan logis yaitu melalui kegiatan eksplorasi sederhana guru atau siswa untuk mengamati suatu objek.

\section{METODOLOGI PENELITIAN}

Penelitian ini dilaksanakan pada tanggal 9 januari-19 februari 2017 dengan sumber data penelitian anak kelompok B berusia 5-6 tahun berjumlah 15 orang. Jenis penelitian ini menggunakan penelitian tindakan (action research). Desain dalam penelitian ini menggunakan Kemmis dan Taggart yang meliputi 4 tahap yaitu tahap perencanaan, tindakan, pengamatan dan refleksi. Dalam model Kemmis dan Taggart tindakan dan observasi dijadikan sebagai suatu kesatuan yang tidak dapat terpisahkan. Teknik pengumpulan data yang digunakan dalam penelitian ini adalah observasi, catatan lapanagan dan dokumentasi.

Lembar instrument yang telah disiapkan oleh peneliti berisika

\section{HASIL DAN PEMBAHASAN}

Analisis data secara kuantitatif dilakukan dengan melihat adanya persentase peningkatan perhatian terfokus mulai dari pra indikator-indikator yang merupakan acuan dalam penilaian Kreativitas anak berusia 5-6 tahun. Instrument ini diisi oleh penelitian dan kolaborator dengan memberikan tanda check list $(\sqrt{ })$ pada setiap indikator yang sesuai dengan tingkatan Kreativitas yang muncul pada anak.

$$
\text { Pengolahan data dalam }
$$
penelitian ini menggunakan dua analisis data yaitu analisis data kuantitatif dan analisis data kualitatf. Analisis data kuantitatif menggunakan statistik deskriptif dengan cara membandingkan hasil yang diperoleh pada pra siklus sampai siklus II. Analisis data kualitatif dilakukan dengan cara menganalisis data dari hasil catatan lapangan, observasi dan dokumentasi dengan langkah-langkah reduksi data, display data dan verifikasi data.

Siklus, Siklus I dan Siklus II dengan mengamati Kreativitas anak. Berikut data Kreativitas anak. 
Tabel 4.21 Data Kreativitas anak usia 5-6 tahun

Di PAUD SPS Arrayyan Palembang tahun 2017

\begin{tabular}{|c|c|c|c|}
\hline Skor & Pra Siklus & Siklus I & Siklus II \\
\hline Rata-rata & 24,9 & 44,9 & 67,2 \\
\hline Peningkatan & & 20 & 22,3 \\
\hline
\end{tabular}

Melihat hasil penelitian diatas, berbicara tentang metode pembelajaran inkuiri dan kaitannya dengan kreativitas sesuai dengan variavel yang diteliti oleh peneliti. Hal ini sesuai dengan apa yang dikatakan Alkaterini Michalopoulou. Dalam penelitiannya yang berjudul Inquiry-Based Learning through the Creative Thingking and Expression in Early Years Education. Menjelaskan bahwa: Dalam penelitiannyauntuk meningkatkan kreativitas anak, dengan cara eksplorasi dengan tema yang menarik, dengan eksplorasi yang dilakukan anak dapat memberikan tanggapannya, pikiran, gagasan dan perasaan anak melalui seni menggambar. Dengan gambar yang anak lakukan di harapkan anak dapat mengekspresikan ide-ide dengan cara menceritakan gambar tersebut, sehingga anak dapat berimajinasi.
Kreativitas anak berkembang adalah salah satu cara yang dilakukan guru yaitu bagaimana menciptakan pembelajaran inkuiri menjadi menarik, guru merancang, mempersiapkan bahan, melaksanakan kegiatan dengan tahap usia anak, anak memiliki imajinasi yang tinggi oleh karena itu dalam melaksanakan kegiatan guru memberikan tema yang menarik, dan berbeda pada setiap kegiatan. Anakanak mampu membuat produknya setelah menggunakan metode inkuiri, anak-anak membuat produk berupa gambar untuk menceritakan pendapatnya dari kegiatan sebelumnya, anak-anak mengekspresikan diri, mengembangkan daya imajinasinya, berpikir kreatif dalam menghasilkan produk. Salah satu penelitian yang dilakukan peneliti yang bertema "bumi berputa" anak menggambarkan bumi, anak-anak 
mengekspresikan idenya bahwa bumi memiliki keindahan seperti bumi penuh dengan bunga, bumi tempat bersuka ria bersama keluarga, bumi memiliki banyak air, bumi penuh dengan warna, bumi penuh dengan tumbuhan, dan pepohonan. Hong-Yi le. Inquiry-Based Teaching in Second and Foreign Language Pedagody. Penelitian ini menunjukkan bahwa mengajar berbasis inkuiri dapat menginspirasi dan mampu mengembangkan kemampuan siswa dengan melinatkan lingustik dan kognitif mereka. Pertanyaan terstruktur menunjukkan siswa untuk menghubungkan, menerapkan, menganalisis, dan menciptakan. Beberapa variabel yang mungkin mempengaruhi keberhasilan pelaksananan pengajaran berbasis inkuiri termasuk pembelajaran kelompok, dan kemampuan untuk menciptakan lingkungan belajar yang santai dan menyenangkan.

Penggunaan metode inkuiri yang dilakukan dengan cara bermain menjadikan pembelajaran inkuiri menjadi menyenangkan, anak-anak bermain sesuai dengan tema kegiatan pada hari itu, anak bisa bermain membentuk lingkaran, bermain drama, dan bernyanyi bersama. Kegiatan inkuiri juga memberikan kebebasan untuk anak berekspresi, antusias anak-anak terhadap penggunaan media yang digunakan. Pembelajaran inkuiri tidak hanya meningkatkan kreativitas anak tetapi juga kontribusi terhadap kosakata anak, social, dan kognitif anak, karena dengan metode inkuiri anak melakukan aktivitas dengan cara berkelompok sehingga interaksi anak tercipta. Botz Krummeheuer dalam penelitiannya yang berjudul Explaning the mathematical creativity of young boy; an interdisciplinary venture between mathematics education and psychoanalysis menjelaskan bahwa kreativitas yang dilakukan denga cara bereksplorasi siswa melalui lingkunganya, dan guru juga menggunakan metode bermain untuk meningkatkan anak dalam pembelajaran matematika.

Secara tidak langsung metode pembelajaran inkuiri juga berdampak pada kemampuan kognitif anak, dalam hal ini anak-anak menghitung 
bahan-bahan yang dijadikan eksplorasi, salah satunya pada kegiatan mengamati ulat kaki seribu, dan mengamati belalang, anak mengenal konsep banyak sedikit. Kegiatan "benda terapung, melayang, tenggelam" mengenalkan anak konsep berat ringan.

Angela Eckhoff dalam penelitiannya yang berjudul Creativity In EarlyChidhood Classroom: menjelaskan bahwa peran guru sangat mempengaruhi anak dalam mengembangkan kreativitas, adapun kreativitas yang dikembangkan yaitu melalui seni, contoh kegiatan seni yang di lakukan antara lain seni melukis, seni menggambar yang bertujuan agar anak berpikir imajinatif. Didalam pembelajaran inkuiri, guru harus aktif merancang, kegiatan pembelajaran, menyiapkan media dan bahan-bahan sumber pembelajaran. Sehingga memunculkan kreativitas anak melalui seni menggambar dan seni drama. Anna Lehtonen. at. al dalam penelitiannya yang berjudul Promoting Creativity In Teaching Drama menjelaskan bahwa pembelajaran kreatif dapat ditingkatkan melalui kegiatan drama. Guru perlu mempersiapkan proses kegiatan pembelajaran yang kreatif, dimana hasil dari kegiatan tersebut tidak dapat atau diluar prediksi guru. Melaluidrama, tujuan guru untuk memberikan dan membuat waktu dan tempat sebagai solusi dan ide kreatif dalam pembelajaran drama. Drama juga dapat dijadikan sebagai kegiatan yang baik untuk berkolaborasi dan meningkatkan kepedulian siswa. Melalui pembelajaran inkuiri, perkembangan seni meningkat dalam seni drama. Salah satu contoh seni drama pada kegiatan "mengamati Belalang". Dari kegiatan inkuiri anak-anak menghasilkan produk berupa wayang belalang, kemudian anak-anak menggunakan produknya untuk dipakai pada kegiatan drama.

\section{KESIMPULAN DAN SARAN}

Kegiatan inkuiri dapat digunakan dalam peningkatan kreativitas anak. Anak biasanya belajar di sekolah dengan menggunakan calistung dan berfokus pada guru (teacher center). Dalam kegiatan belajar mengajar guru 
memberikan sedikit kesempatan kepada anak untuk meningkatkan kreativitas anak dalam mengungkapkan ide, menghasilkan produk, dan mampu menceritakan hasil kegiatan yang telah dilakukan.

Pembelajaran akan lebih baik, jika menggunakan metode pembelajaran inkuiri. Dengan menggunakan kegiatan metode pembelajaran inkuiri anak dapat bereksplorasi menggunakan berbagai bahan atau media di lingkungan sekitar atau sekolah. Dalam kegiatan pembelajaran ini guru lebih sebagai fasilitator dan memberikan motivasi kepada anak agar kreativitas anak lebih meningkat. Dari hasil pembahasan dan kesimpulan pada penelitian ini, ditemukan bahwa terdapat peningkatan kreativitas anak usia 5-6 tahun melalui metode pembelajaran inkuiri di PAUD SPS Arrayyan Palembang. Hasil penelitaian dapat disimpulkan bahwa Kreativitas anak dapat lebih meningkat dengan metode pembelajaran inkuiri.

Secara teoritis hasi penelitian ini, memberikan suatu gambaran mengenai peningkatan kreativitas anak melalui metode pembelajaran inkuiri. Kreativitas anak memilliki peranan penting yang dimiliki setiap anak usia dini khususnya, sehingga diperlukan perhatian dan metode yang tepat, agar kreativitasanak dapat meningkat. Kreativitas anak dapat meningakat dan dapat dipengaruhi, salah satunya orangorang yang ada disekitar anak, serta guru dituntut kreatif untuk menyiapkan bahan dan sebagai fasilitator, agar terciptanya generasi yang kreatif. Kreativitas yang dimiliki anak tidak hanya menyangkut rasa percaya diri anak terhadap produk yang dihasilkan, tetapi juga anak mampu mengungkapkan ide, anak aktif menghasilkan produk, dan anak dapat menceritakan kegiatan yang anak lakukan.

Dari penelitian ini menghasilkan implikasi berkenan perencanaan dan metode yang dipakai di pembelajaran Pendidikan Anak Usia Dini. Temuan penelitian ini menyatakan bahwa metode pembelajaran inkuiri dapat meningkatkan Kreativitas anak dibandingkan kegiatan pembelajaran 
yang telah dilakukan berfokus hanya kepada guru, dan menekankan baca tulis dan berhitung, tanpa memberikan kesempatan untuk melakukan sesuai dengan tahap usia anak, yaitu dengan cara bermain. Dalam kegiatan metode pembelajaran inkuiri, guru berperan

\section{DAFTAR PUSTAKA}

Alkaterini Michalopoulou. 2014. Inquiry- Based Learning through the Creative Thingking and Expression in Early Years Education. Departement of Early Years Education, University of Thessaly, Thessaly, Greece. Creative Education, 2014,5,377-385.

Horng-Yi Lee. (2014). Inquiry-based Teaching in Second and Foreign Language Pedagogy. ISSN 1798- 4769. Journal of Language Teaching and Research, Vol 5, No. 6,pp. 1236-1244, November 2014. (C) 2014

ACADEMY

PUBLISHER Manuafacture in Finland.

Botz Krummeheur. (2013). Explaning the Matematical Creativity of Young Boy: An Interdisiplinary Venture Between Mathematics Education and Psychoanalysis. Education Stud Math84.183199. DOI 10.007, 5 10649-0139505-3.

Angela Eckhoff. (2011.)Creativity In Early Chidhood Classroom: Perspectives Of Preservice penting sebagai pendidik dan fasilitator, guru menyiapkan media pembelajaran dan metode pembelajaran yang kreatif, sehingga menghasilkan suasana pembelajaran yang menyenangkan dan kreatif.

Teachers. Jounal of early childhood teacher education,32:240-255,

Copyright (c) National association of Early Childhood Teacher Educator ISSN; 10901027 print/ $1745-5642$ online.

Lehtonen, Anna et,al. (2013).Creative pedagogySupporting Children's Creativty Throught Drama. The European Journal of Social \& Behavioral Sciences (EJSBS) Eissn: 2301-2218.

Geoffrey E. Mills, 2000.Actions research: A Guide for the Teacher Researcher (New Jersey: Pearson Education),h.6.

Ernest T. Stringer, Action research Third Edition (London. Sage Publication, Inc. 2007), h.1.

James Schreiber \& Kimberly AsnerSelf. Educational Research (United States of America: John Wiley \& Sons, Inc).

James Schreiber \& Kimberly AsnerSelf, loc.cit

George S.Morrison.(2012). DasarDasar Pendidikan Anak Usia Dini.Jakarta:Indeks.

Porandokht Fazelian, Saber Azimi. (2013). Creativty in Schools. Sciverse ScienceDirect. Procedia- Social and 
PERNIK Jurnal PAUD, VOL 1 NO.1 September 2018

Behavioral Sciences 82 719-

723.

Koster Joan Bouza. (2012). Growing Artists Teaching the Arts to Young Children. Canada.

Premedia Global. 
PERNIK Jurnal PAUD, VOL 1 NO.1 September 2018 